\title{
Aplicação do lúdico para o ensino de saúde na educação médica da cidade de Parnaíba, Piauí: relato de experiência
}

\author{
Playful application for health education in medical education in the city of Parnaíba, Piauí: \\ experience report
}

\begin{abstract}
Aplicación lúdica para la educación sanitaria en educación médica en la ciudad de Parnaíba, Piauí: informe de experiencia
\end{abstract}

Tom Ravelly Mesquita Costa ${ }^{1 *}$, João Dutra de Araujo Neto ${ }^{1}$, Amanda Azevedo Torres ${ }^{1}$, Victor Trindade da Cruz ${ }^{1}$, Rafael Santos Correia ${ }^{1}$, Daniela Winckler Mass ${ }^{1}$, Pedro Henrique dos Santos Silva ${ }^{1}$, Andréia Ferreira dos Santos ${ }^{1}$, Wanessa Cândida de Paula ${ }^{1}$, Karina Rodrigues dos Santos ${ }^{1}$.

\section{RESUMO}

Objetivo: Demonstrar pelo relato de experiência de um grupo de acadêmicos do terceiro período do curso de Medicina da Universidade Federal do Delta do Parnaíba (UFDPar), Parnaíba-PI, a importância do lúdico no processo de ensino-aprendizagem, assim como, identificar de que forma tais metodologias de aprendizagem atravessam a formação dos discentes do curso. Relato de Experiência: As estratégias escolhidas para a elaboração das atividades foram o teatro de fantoches e duas paródias musicais, descritos, desde a definição do método lúdico, a elaboração de um roteiro de apresentação e a confecção de materiais, até a sua execução para os demais alunos. Desse modo, o material e conteúdo produzido foi apresentado na respectiva aula do módulo de parasitologia e microbiologia. A divisão decorreu em dois momentos, iniciou-se com a peça teatral, evidenciando a importância da prevenção e promoção da saúde. A segunda etapa constava das paródias, que de forma interativa, repassava informações. Considerações Finais: Por intermédio da aula, foi possível utilizar metodologias lúdicas para o ensino médico. Dessa forma, conclui-se com uma reflexão acerca da relevância do lúdico, tornando-se primordial a estimulação da comunicação entre os âmbitos da cognição humana, criatividade e a importância da interação com o objeto de estudo.

Palavras-chave: Educação médica, Parasitologia, Recreação.

\begin{abstract}
Objective: To demonstrate the experience report of a group of academics from the third period of the medical course at the Federal University of Delta do Parnaíba (UFDPar), Parnaíba-PI, the importance of playfulness in the teaching-learning process, as well as identifying what forms such learning methodologies cross the formation of the students of the course. Experience Report: The strategies chosen for the elaboration of the activities were the puppet theater and two musical parodies, described, from the definition of the playful method, the elaboration of a presentation script and the making of materials, until its execution for the students. other students. In this way, the material and content produced was presented in the respective class of the parasitology and microbiology module. The division took place in two stages, starting with the play, showing the importance of prevention and health promotion. The second stage consisted of parodies, which interactively passed on information. Final Considerations: Through the class, it was possible to use playful methodologies for medical teaching. Thus, it concludes with a reflection on the relevance of playfulness, making communication between the areas of human cognition, creativity and the importance of interaction with the object of study paramount.
\end{abstract}

Keywords: Medical education, Parasitology, Recreation.

\section{RESUMEN}

Objetivo: Demostrar el informe de experiencia de un grupo de académicos del tercer período del curso de medicina en la Universidad Federal de Delta do Parnaíba (UFDPar), Parnaíba-PI, la importancia de la diversión en el proceso de enseñanza-aprendizaje, así como identificar qué formas de tales metodologías de

${ }^{1}$ Universidade Federal do Delta do Parnaíba (UFDPar), Parnaíba - PI. *E-mail: tomravelly@gmail.com 
aprendizaje cruzan la formación de los alumnos del curso. Informe de experiencia: Las estrategias elegidas para la elaboración de las actividades fueron el teatro de marionetas y dos parodias musicales, descritas, desde la definición del método lúdico, la elaboración de un guión de presentación y la elaboración de materiales, hasta su ejecución para los alumnos. otros estudiantes De esta forma, el material y el contenido producido se presentaron en la clase respectiva del módulo de parasitología y microbiología. La división tuvo lugar en dos momentos, comenzando con la obra, mostrando la importancia de la prevención y la promoción de la salud. La segunda etapa consistió en parodias, que transmitieron interactivamente información. Consideraciones finales: A través de la clase, fue posible utilizar metodologías lúdicas para la enseñanza médica. Por lo tanto, concluye con una reflexión sobre la relevancia del juego, haciendo primordial la comunicación entre las áreas de cognición humana, creatividad y la importancia de la interacción con el objeto de estudio.

Palabras clave: Educación médica, Parasitología, Recreación.

\section{INTRODUÇÃO}

A inovação na educação médica é primordial para se adquirir uma formação acadêmica completa. Nas últimas décadas, novos métodos de ensino e aprendizagem se desenvolveram e, assim, tornaram-se ferramentas essenciais no modelo didático-pedagógico ministrado pelos educadores. Diante disso, na literatura, as evidências científicas demonstram que a participação ativa dos alunos corrobora na assimilação e consolidação de novos conhecimentos, além de melhorar os resultados do ensino.

Ademais, os estudos afirmam que a informação deve ser fornecida simultaneamente em modalidades multissensoriais, pois tal estratégia é considerada completa, o que é evidenciado na forma em que é ofertado o conhecimento, o qual atende aos múltiplos estilos de aprender, sejam visuais, auditivos ou cinestésicos (REZENDE-FILHO FM, et al., 2014; SCHMIDT HG, et al., 2011).

O processo educativo, na atualidade, demonstra-se com formatos diferenciados, uma vez que os alunos necessitam direcionar o seu enfoque para aprender novas competências e habilidades e isso, sem dúvidas, requer um aperfeiçoamento nos modelos de ensino. Na educação médica essa renovação é imprescindível a ser efetivada, entretanto, alguns obstáculos, como a grande carga de conteúdos curriculares e a grade de aulas exaustivas, são motivos de difícil adesão das novas metodologias.

Todavia, o advento de novas formas metodológicas de abordagem torna-se alvo promissor ao desenvolvimento do ensino. Sendo assim, o incremento dessas atividades na academia é essencial visto que, assim, a construção do conhecimento será conduzida de forma mais dinâmica e atrativa (BERBEL NA, 2016; BORGES T e ALENCAR G, 2014).

As atividades lúdicas representam, segundo Freitas PE, et al. (2014) e Schmidt HG, et al. (2011), a ferramenta que estimula a criatividade e o conhecimento. Nesse sentido, esses métodos, mediante jogos, histórias, teatros entre outros, provocam nos alunos o interesse de participar e, por conseguinte, o processo de aprender novos conceitos, os quais estão envolvidos na ação realizada. Vale também ressaltar o valor dessas metodologias enquanto objetos no direcionamento para possibilitar o aperfeiçoamento de competências e habilidades viáveis a convivência na sociedade atual (FREITAS PE, et al., 2014; SCHMIDT $H G$, et al., 2011).

Os discentes costumam apresentar indiferença pelas metodologias convencionais aplicadas que, frequentemente, são apresentadas de maneira expositiva, isto é, de forma monótona e passiva de ação, com a execução de formas tradicionais como, por exemplo, aulas ministradas apenas de forma expositiva. Concomitante a isso, os docentes questionam o interesse e a falta de participação dos alunos.

Desse modo, nota-se a importância da inserção de metodologias que viabilizem uma interação entre professor e aluno (CAMARGO F e THUINIE D, 2018). Sendo assim, os educandos adquirem um sentimento de desmotivação diante das dificuldades no processo de ensino-aprendizado e isso, certamente, decorre dos métodos passivos, ainda em uso pelos docentes (BACICH L e MORAN J, 2018). Os docentes precisam se adequar ao uso de novas metodologias, tornando o ensino mais atrativo e significativo para 0 aluno. $O$ professor deve ir à procura de auxílios pedagógicos atuais, além de apresentar um envolvimento conjunto com os alunos, desenvolvendo o sentimento de fazer parte da atividade proposta. 
Dentre os meios, pode-se fazer o uso de metodologias ativas como exemplo, metodologias lúdicas e isso, certamente, promoverá a sociabilidade, como também será fator de incentivo da criatividade, reflexividade e construção do conhecimento, assim, os alunos poderão construir conhecimento de forma integral e participativa (MARANHÃO KM e REIS ACS, 2019; PEREIRA MLAS, et al., 2019).

Desse modo, partindo da temática do estudo, objetivou-se demonstrar pelo relato de experiência de estudantes de Medicina, a importância do lúdico no processo de ensino aprendizagem, assim como identificar de que forma tais metodologias de aprendizagem atravessam a formação dos discentes do curso. Decerto, 0 método utilizado pelos alunos na atividade idealizada se transforma em artifícios para a prática pedagógica.

\section{RELATO DE EXPERIÊNCIA}

Trata-se de um estudo qualitativo descritivo no modelo de relato de experiência. A vivência que possibilitou a sua elaboração ocorreu na Universidade Federal do Delta do Parnaíba (UFDPar) com alunos do terceiro período do curso de Medicina, no módulo de Bases dos Processos de Agressão Defesa e Proteção II (BPAD II), no qual são lecionadas as disciplinas de Microbiologia e Parasitologia.

Na grade curricular do módulo BPAD II é proposto aos alunos que, a partir de um conteúdo previamente definido, seja elaborada uma metodologia lúdica de ensino para apresentação aos demais acadêmicos. Ao grupo de dez alunos, juntamente com a professora, os quais compõem a vivência apresentada no presente trabalho, foi proposta a construção do método a partir do conteúdo das arboviroses (dengue, Zika e Chikungunya), teníase e criptococose.

No primeiro momento, o grupo de alunos se reuniu com o objetivo de definir a abordagem que seria elaborada. Após a discussão dos prós e contras de cada uma das metodologias apresentadas pelos integrantes do grupo, definiu-se que o teatro de fantoches seria a que permitiria a maior eficiência e a maior gama de possibilidades para o repasse dos conteúdos (Figura 1).

Figura 1 - Fluxograma da seleção do tema e da metodologia lúdica.

- Apresentação do tema proposto para elaboração de metodologia lúdica;

Escolha da metodologia

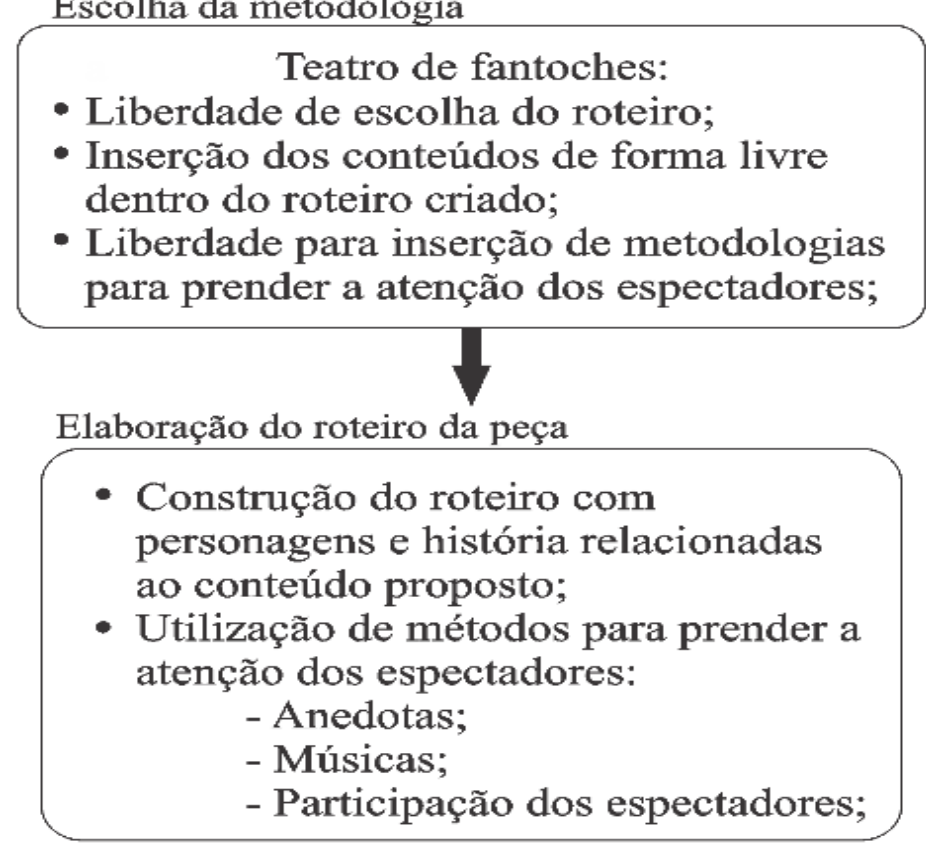

Fonte: Costa TRM, et al., 2020 
Após a escolha da abordagem proposta, o grupo se reuniu para criar o roteiro que seria seguido e definir como o conteúdo proposto seria abordado. Para a construção do roteiro do teatro de fantoches, os acadêmicos se propuseram a criar cenas e personagens que possibilitasse a abordagem de características específicas às doenças abordadas: vetores, sinais e sintomas, fatores de risco, prevenção e importância de ações no controle dessas doenças. Desse modo, a peça foi estruturada em três (3) cenários e contou com a participação de nove (9) personagens (Figura 2)

Figura 2 - Fluxograma da seleção do tema e da metodologia lúdica.

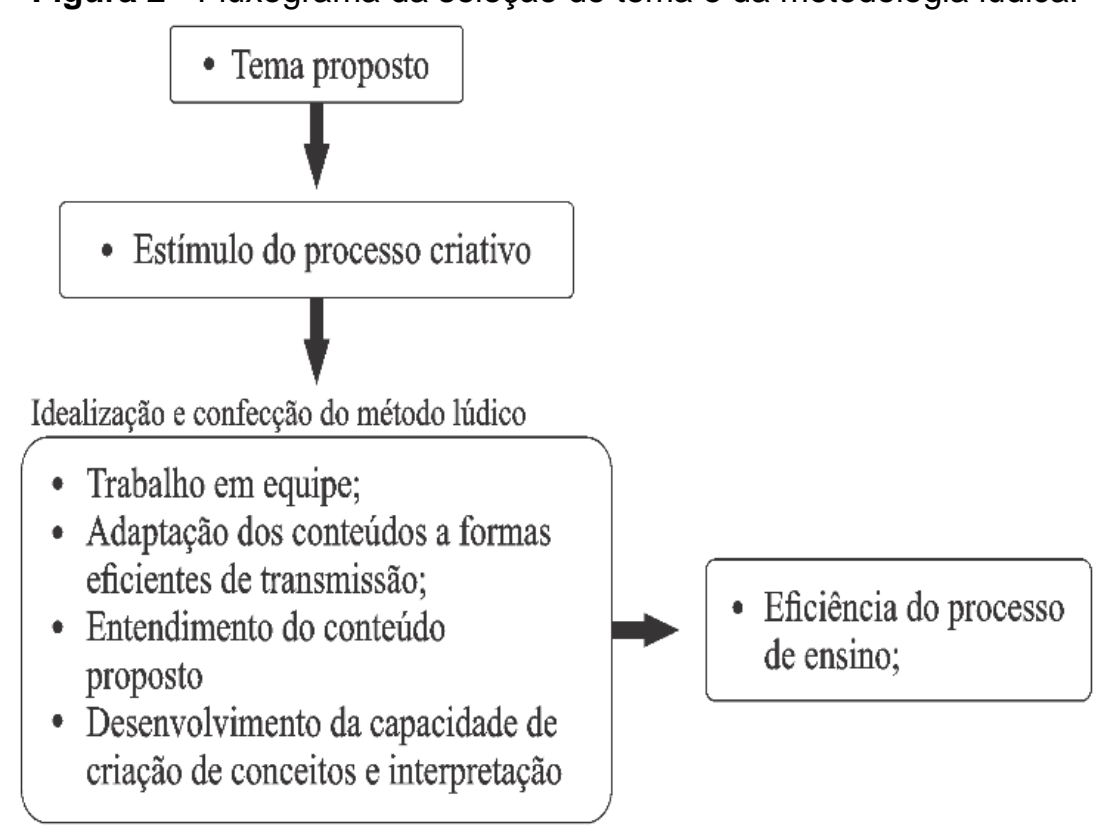

Fonte: Costa TRM, et al., 2020.

Os personagens e cenários que viriam a ser utilizados na apresentação teatral para os demais alunos foram projetados e confeccionados à mão pelos próprios alunos. Os materiais utilizados foram: meias, pincéis, tintas, lápis, canetas, lã, tecido não tecido (TNT), canos de PVC, folhas de acetato-vinila de etileno (EVA) e olhos de plástico (Figura 3).

Figura 3 - Cenários e Fantoches.

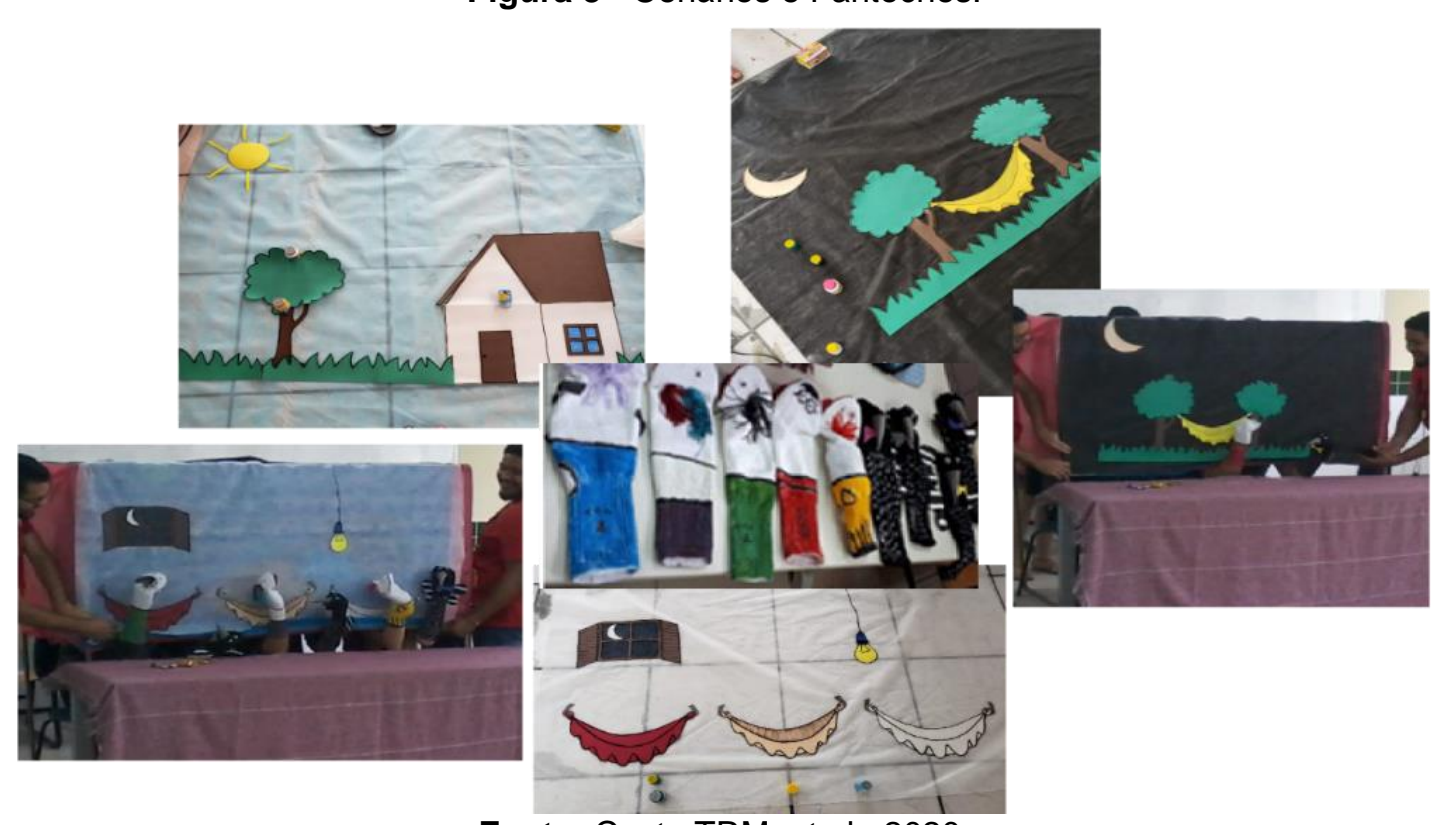

Fonte: Costa TRM, et al., 2020. 
Optamos pela metodologia do teatro de fantoches adicionando paródias musicais, como uma das estratégias para capturar a atenção do público, durante a apresentação os demais alunos mantiveram-se concentrados e interagindo em vários momentos. Ao abordar o tema de arboviroses com o título "Dengue e suas amigas", apresentou-se a história fictícia da família Silva (Strongyloides, o pai, Gardnerella, a mãe, Rickettsia, a filha adolescente e Chaguinhas, o filho mais novo), que adoeceram após serem infectados pelos vírus causadores da febre amarela, Zika, Chikungunya e dengue, respectivamente. Foram abordadas a prevenção, as causas, a evolução e os sintomas de tais enfermidades.

A montagem do enredo envolveu diversos componentes como: o cenário, os bonecos, as músicas, os efeitos sonoros e o roteiro. Para a trilha sonora e a produção artística dos cenários e personagens foram tomados alguns cuidados, tais como edição, montagem conforme o enredo, caracterização dos fantoches com cores que transmitisse alegria e descontração. A fala dos personagens foi adaptada para rememorar uma típica família nordestina, com seus sotaques e expressões linguísticas singulares. Dessa forma, a apresentação tornou-se engraçada e convidativa, facilitando a aproximação da plateia, prendendo a atenção e propiciando uma efetiva absorção do conteúdo trabalhado de forma lúdica.

Figura 4 - Fluxograma do planejamento do roteiro e definição dos personagens.

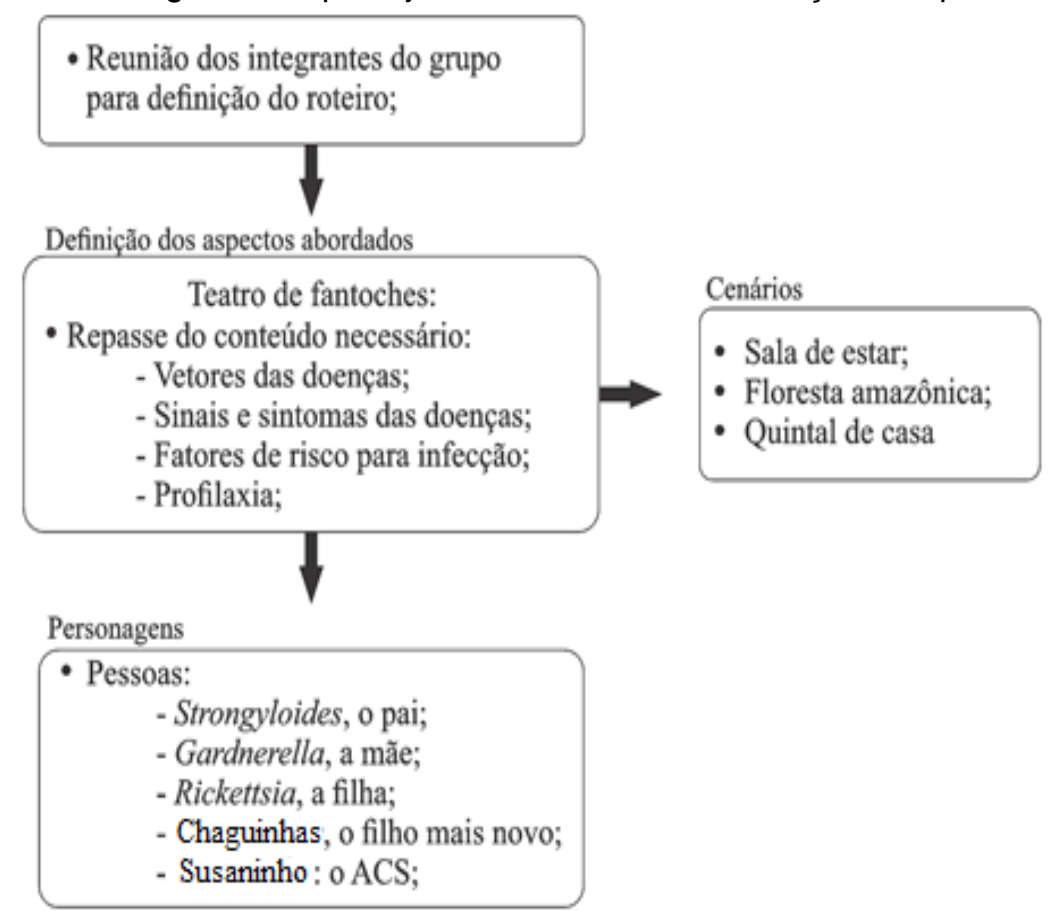

Fonte: Costa TRM, et al., 2020.

O público-alvo da atividade foi composto pelos estudantes que promoveram a atividade, estes ampliaram seu conhecimento durante o processo da produção intelectual e material da metodologia, além de outros 25 alunos e professores do módulo de BPAD II, ambos os grupos pertencentes ao curso de graduação de Medicina, terceiro período da UFDPar. Na data definida para a apresentação do teatro aos demais alunos da turma, o grupo de acadêmicos o fez da forma programada, seguindo o roteiro, o qual se encontra inserido nas informações suplementares no arquivo do artigo, com o objetivo principal de repassar o conteúdo predefinido. Para isso, os alunos propuseram a organização da peça de modo que cada cena tivesse partes capazes de recuperar a atenção dos espectadores, o que foi feito por meio de metáforas, de músicas ou da participação ativa da plateia.

Ademais, foi promovido duas paródias sobre teníase e criptococose (Figura 5) que serviram de apoio para o entendimento e inserção dos alunos no contexto da atividade, além de abordar e interligar diferentes conteúdos presentes na disciplina. Com atividades concomitantes e alternadas, de teatro, música e explicação, o conhecimento foi construído e compartilhado de forma dinâmica com interação dos demais alunos da sala. 
Para a criação das paródias, buscou-se músicas populares que pertencem ao cotidiano dos discentes da turma de forma atual ou nostálgica, a fim de aproximá-los do conteúdo apresentado (SANTOS GG, 2019). Durante a criação, foi alterado a letra, introduzindo os conceitos escolhidos e ministrados na disciplina ao longo do período, se preocupando em ajustá-las à melodia de tal forma que se tornasse agradável aos ouvidos dos espectadores. As paródias foram acompanhadas por um violão e cantadas pelos integrantes do grupo, estimulando a apreensão dos conteúdos por tornar o ambiente mais interessante e prazeroso.

Durante a atividade de metodologia ativa, foi notória a maior participação e compreensão dos alunos que assistiam à apresentação, o que nos permite inferir que ações lúdicas nas salas de aulas motivam a aprendizagem dos assuntos abordados na disciplina BPAD II. Isso leva a crer que o lúdico é um instrumento importante do conhecimento dos recursos pedagógicos de uma disciplina (MESQUITA AL, et al., 2016).

Figura 5 - Paródias.

O nome dela é taenia

Mas ela veio do almoço

Com a carne mal passada

Quem é essa lombriga aí?

Mas "peraí", mas "peraí"

Eu "tô" sentindo uma fraqueza

Dia todo no banheiro

Náuseas e dor estão aqui

Mas mesmo assim, vou lhe expulsar

O nome dela é Taenia

Eu encontrei ela no bife

Ela não foi convidada

Mas quer permanecer

O nome dela é Taenia

Ela gostou do meu intestino

Tem a solium e a saginata

$\mathrm{O}$ que eu não passo com vocês

O nome dela é Taenia

Fui na UBS pra saber

Eu vou tomar niclosamida

Ela vai desaparecer
A lenda do pombo solitário

Bem lá no céu, um pombo existe

Vivendo só, no seu mundo triste

O seu olhar sobre o parque lançou

Veio espalhar o seu cocô

Então o pseudosporo tão pequenininho

Se cansou de ficar sozinho

E pelo ar vai se disseminar

E pelo seu nariz vai entrar

Inala meus esporos

Faço tudo acontecer

Te mostro como eu amo você

Se existir infecção

Vou tossir vou vomitar

Se espalhar só Deus sabe

Se o antifúngico eu tomar

Vou poder melhorar

Criptococose se afaste!

Fonte: Costa TRM, et al., 2020.

\section{DISCUSSÃO}

Nos dias atuais, a educação formal enfrenta impasses que cada vez mais têm demonstrado a necessidade de evolução e mudanças dos currículos e metodologias de ensino. A sociedade como um todo passa constantemente por mudanças, evoluindo em características e necessidades, fato que torna necessário que serviços e organizações se adaptem de forma contínua. Nesse sentido, a formulação da educação tradicional, que ensina e avalia todas as pessoas de forma unificada e exige resultados predefinidos, tem se mostrado obsoleta e ineficaz (MORÁN J, 2015).

Nesse cenário, a aplicação de metodologias ativas na educação destaca-se como uma ferramenta extremamente poderosa. O curso de medicina da UFDPar, seguindo o que é preconizado pelas diretrizes dos novos cursos de medicina do Brasil, dá enfoque especial à utilização dessas metodologias (PEDROSA JIS, 2019).

Ao fornecer ao educador e ao educando uma elevadíssima gama de propostas pedagógicas, as metodologias ativas constroem no espaço do ensino um ambiente onde o aluno atua como voz ativa na construção do seu conhecimento, estando cada vez mais preparado para o enfrentamento de situações exigidas pelo exercício profissional (BERBEL NA, 2011). 
Entre as metodologias ativas mais utilizadas atualmente, encontram-se as propostas pedagógicas de ensino lúdico. Os métodos lúdicos de ensino, como o desenvolvido pelos alunos do curso de Medicina da UFDPar, têm demonstrado eficiência no processo de construção do conhecimento por permitirem a comunicação entre diversos âmbitos da cognição humana, estimulando o desenvolvimento da linguagem (verbal e não-verbal), da personalidade, da interpretação e coordenação (MIRANDA S, 2001).

A vivência obtida pelos acadêmicos como construtores do processo de ensino de modo individual e coletivo demonstrou como a sua aplicação é importante para o desenvolvimento de senso crítico, é capaz de estimular a criatividade e, sobretudo, é eficaz no processo de assimilação do conhecimento. A estruturação do processo de confecção da metodologia em três etapas foi capaz de permitir a visualização clara dessa relação.

Durante a assimilação dos conteúdos e conversão em projeto de metodologia lúdica, os alunos foram convidados a desenvolver sobre o processo educativo um olhar diferente do que estavam acostumados. $\mathrm{O}$ processo de aprendizagem ativa se caracteriza como os métodos que possibilitam que o aluno interaja com o objeto de estudo - ouvindo, falando, perguntando, discutindo fazendo e ensinando (BARBOSA EF e DE MOURA DG, 2013).

Com relação ao uso de técnicas de ensino consideradas inovadoras, além da associação da ludicidade e aquisição de conhecimento, outra metodologia ativa, fazer a junção do processo intelectual à emoção, criatividade, espontaneidade, expressões artísticas corporais e musicais se torna algo extremamente desafiador. Não existe dúvida de que, a apresentação de temas da área médica em consonância com o lúdico, motivou e oportunizou uma participação ativa dos discentes, permitindo-lhes o desenvolvimento de habilidades de comunicação e de criatividade.

Além disso, proporcionou uma aproximação entre os alunos da mesma equipe e destes com os docentes responsáveis pelos componentes curriculares. Os discentes sempre destacam esta atividade como importante ferramenta no tocante à formação deles e, também, representa um momento oportuno para certa descontração no semestre letivo. A motivação nas aulas é de extrema importância, algo que desperta o interesse no aprender e envolve um relacionamento mais intenso professor-aluno (LIMA A, et al., 2019).

O observado durante a idealização do projeto foi que o incentivo ao entendimento do conteúdo e a formulação de uma aplicação prática pelos próprios alunos foi responsável por promover o entendimento concreto do conteúdo e possibilitar uma adaptação muito mais eficaz às suas reais necessidades (Figura 5). Desse modo, como analisou Fialho NN (2007), a experiência de criação de um método lúdico pelos acadêmicos permitiu a elaboração de conceitos e a fixação de conteúdo.

No processo de confecção, além da construção propriamente dita do material do teatro e da paródia, outros elementos foram desenvolvidos espontaneamente. A ampliação desses itens se faz necessária e importante para a vivência, não só acadêmica, mas para a sociedade, aprimorando a forma de ver e interagir com o meio.

Dessa forma, na construção da metodologia de ensino relatada requereu-se, ao mesmo tempo em que melhorou nos envolvidos, a criatividade; as habilidades manuais; a capacidade de trabalho em equipe; a análise crítica; habilidades de comunicação, o estudo com propriedade do conteúdo, bem como a capacidade de tratar de determinado tema de diversas formas, flexibilizando-o (KROEFF MAS e HOPPE L, 2014).

A confecção das atividades lúdicas pelo grupo envolveu um processo de releitura dos temas através de novos paradigmas. Inserir temas como Parasitologia e virologia de forma descontraída foi um tanto desafiador e o olhar sobre o conteúdo teve de ser redimensionado e adaptado para o universo fictício-artístico, remetendo à realidade da população brasileira, que convive e combate as arboviroses e parasitoses diariamente.

A utilização de estratégias alternativas às convencionais pode potencializar o ensino em saúde dos cursos Médicos. A proposta de ludicidade favorece, além da variedade de metodologias e do consequente interesse maior dos estudantes, a criatividade e o diálogo necessários nas atividades planejadas em grupo. Sendo assim, incluir essa possibilidade metodológica na vivência acadêmica de estudantes de Medicina colabora tanto com a trajetória de formação quanto com a futura produção do cuidado em saúde. 


\section{REFERÊNCIAS}

1. BACICH L, MORAN J. Metodologias ativas para uma educação inovadora: uma abordagem teórico-prática. Porto Alegre: Penso, 2018, 260p.

2. BARBOSA EF, DE MOURA DG. Metodologias ativas de aprendizagem na educação profissional e tecnológica. Boletim Técnico do Senac, 2013, 39(2): 48-67.

3. BERBEL NA. As Metodologias Ativas e a Promoção da Autonomia de Estudantes. Semina: Ciências Sociais e Humanas, 2016, 32(1): 25-40.

4. BORGES T, ALENCAR G. Metodologias Ativas na Promoção da Formação Crítica do Estudante: o uso das metodologias ativas como recurso didático na formação crítica do estudante do Ensino Superior. Cairu em Revista: Sociedade, Educação, Gestão e Sustentabilidade, 2014, 3(4): 119-143.

5. CAMARGO F, THUINIE D. A sala de aula inovadora: estratégias pedagógicas para fomentar o aprendizado ativo. Porto Alegre: Penso, 2018, 144p.

6. FIALHO NN. Jogos no Ensino de Química e Biologia. Curitiba: IBPEX, 2007.

7. FREITAS PE, et al. Aplicação de Metodologias Ativas de Ensino na Faculdade de Ciências Gerenciais de Manhuaçu: Relato de Experiência. Revista Científica Internacional, 2014, 1(29): 51-63, 2014.

8. KROEFF MAS, HOPPE L. Revista Veras, São Paulo, 2014, 4(2): 164-181.

9. LIMA A, et al. Evaluation, Teaching and Active Methodologies: an Expirience as Part of the Curricular Component Mechanism of Aggression and Defense of the Medicine course of Universidade do Estado da Bahia, Brazil. Revista Brasileira de Educação Médica, Brasília, 2019, 43(2): 216-224.

10. MARANHÃO KM, REIS ACS. Recursos de gamificação e materiais manipulativos como proposta de metodologia ativa para motivação e aprendizagem no curso de graduação em odontologia. Revista Brasileira de Educação e Saúde, 2019; 9(3): 1-07.

11. MESQUITA AL, et al. Metodologias lúdicas aplicadas ao curso de medicina. Revista Educação em Saúde, 2016; 3(suplemento 2): $44 p$.

12. MIRANDA S. No Fascínio do jogo, a alegria de aprender. In: Ciência Hoje, 2001; 28: 64-66.

13. MORÁN J. Mudando a educação com metodologias ativas. Coleção mídias contemporâneas. Convergências midiáticas, educação e cidadania: aproximações jovens, 2015; 2(1): 15-33.

14. PEDROSA JIS. Implantação e desenvolvimento do curso de Medicina em Parnaíba (PI), Brasil, a partir do Programa Mais Médicos para o Brasil. Interface (Botucatu), 2019; 23(suplemento 1): 1-15.

15. PEREIRA MLAS, et al. Interdisciplinaridade em Saúde Coletiva: construção de um recurso didático no campo da prática profissional. Revista Brasileira de Educação e Saúde, 2019; 9(4): 77-83.

16. REZENDE-FILHO FM, et al. A student-centered approach for developing active learning: the construction of physical models as a teaching tool in medical physiology. BMC Med Educ, 2014; 14(189):1-9.

17. SANTOS GG. Paródias e histórias em quadrinhos: relato de uma experiência no ensino de química. Anais do Salão Internacional de Ensino, Pesquisa e Extensão - SIEPE, 2019; 10(1): 1-5.

18. SCHMIDT HG, et al. O processo de aprendizagem baseada em problemas: o que funciona e por quê. Med Educ, 2011; 45(8): 792-806.

19. SILVEIRA MP, KIOURANIS NMM. A música e o ensino de química. Química Nova na Escola, 2008; $28: 28-31$.

20. TEIXEIRA AFS. Teatro e Ecologia - Uma proposta arte dramática para o desenvolvimento da responsabilidade ambiental: A educação dramática no ensino fundamental. [Trabalho de Conclusão de Curso]. Londrina (PR): Universidade Estadual de Londrina, 2004. 